\title{
Construction of Seven-Membered Cycles through Base Promoted [4+3] Domino Annulation of Crotonate-derived Sulfur Ylides with Diene
}

\author{
Yang Liu, $\dagger^{*}$ Joost Berkhong† \\ Frontier Institute of Science and Technology (FIST), Xi'an Jiaotong University, Yanxiang Road 99, \\ 710054, Xi'an, China \\ Supporting Information
}

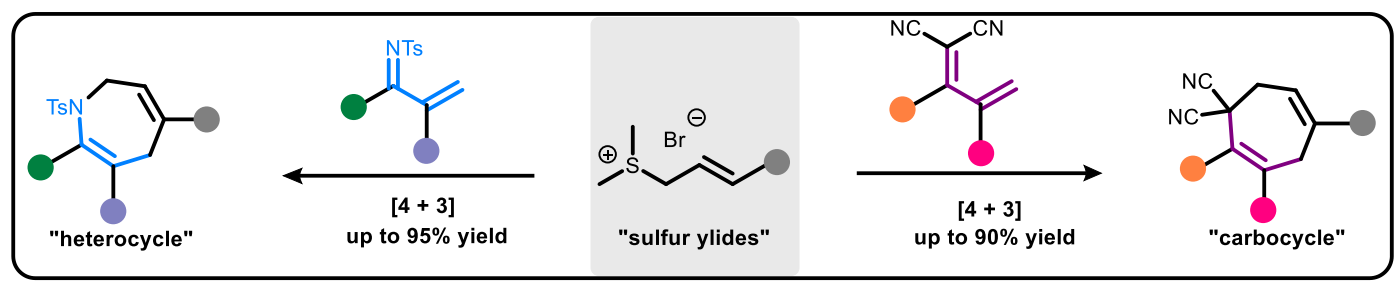

\begin{abstract}
A sequential [4+3] domino annulation of crotonate-derived Sulfur Ylides with Diene has been reported. With base promoted, this general method can realize the synthesis of highly functional none-fused cycles including nitrogen-heterocycles and carbocycles which are widely and important in pharmaceutical molecules with excellent yield respectively, showing a great application potential. Meanwhile, this is also a supplementary to sulfur ylide chemistry as the C3 synthesizer.
\end{abstract}

$\mathrm{S}$ ulfur ylides are among the most significant and widely applied chemical reagents participated in the field of organic synthetic chemistry. ${ }^{1}$ The chemistry of this type of reagents has evolved dramatically over the past 50 years since the pioneering work of Johnson, Corey and Chaykovsky in the $1960 s^{2}$ as the well-known Johnson-Corey-Chaykovsky reaction. Based on that, sulfur ylides can react with polar substrates, for example, aldehydes, ${ }^{3}$ ketones, ${ }^{4}$ imines ${ }^{5}$ and electron-deficient alkenes ${ }^{6}$ to produce a wide range of significant small-ring molecules such as epoxides, aziridines, cyclopropanes and so on ${ }^{7}$. More importantly, their synthetic potential has been well applied in the synthesis of numerous bioactive natural products and pharmaceuticals. ${ }^{8}$ So, developing the novel and extensive methods is greatly meaningful.

In the past decade, sulfur ylide has mainly participated in many cycloaddition reactions but always as the $\mathrm{C} 1$ synthesiz$\mathrm{ers}^{9}$ which are attributed to inherent properties as nucleophilic 1,1-dipolar species as shown in Scheme 1a. Although some elegant work has been reported, the specific structure of sulfur ylides limited the possibility of building large-membered ring molecules.

In order to address this issue, a new type of crotonate-derived sulfur ylide was developed in recent years. ${ }^{10}$ Because of the introduction of allylic part, the negative carbon dipolar would tend to tautomerize to other position with the base involved as the $\mathrm{C} 3$ synthesizers through a domino process (Scheme 1b).

Scheme 1. Recent advances in the catalytic cyclization reactions of sulfur ylides as the $\mathrm{C} 1$ or $\mathrm{C} 3$ synthesizers

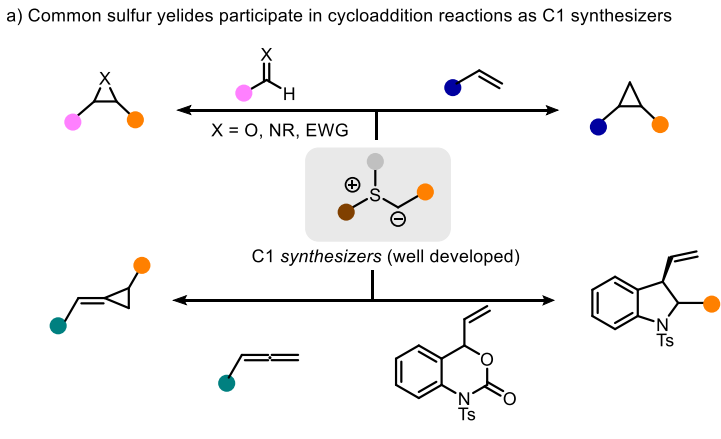

b) Crotonate sulfur yelides participate in cycloaddition reactions as $\mathrm{C} 3$ synthesizers

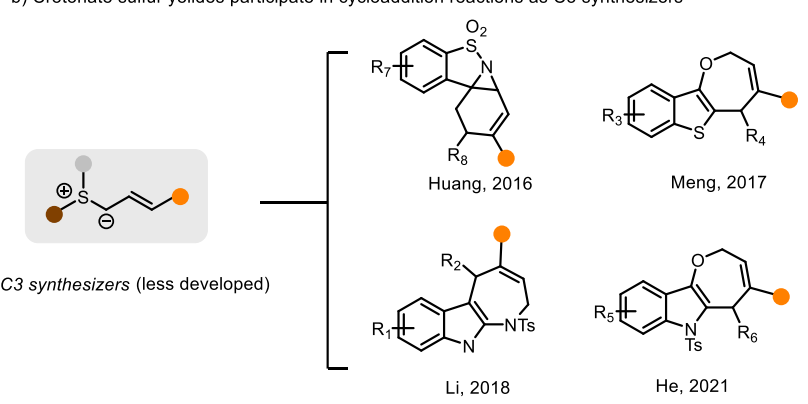

c) This work:Base promoted [4+3] annulation of Crotonate-derived Sulfur Ylides

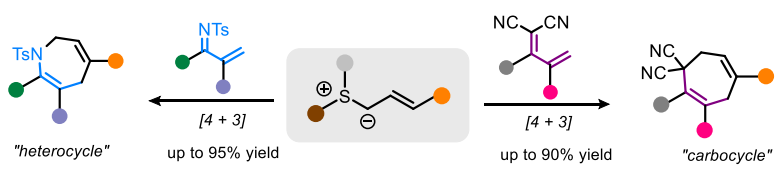


For example, Huang ${ }^{11 a}$ reported a original annulation domino reaction of crotonate-derived sulfur ylide and $\alpha, \beta$-unsaturated cyclic ketimines for the construction of cyclic 2-alkenyl aziridines. Meng ${ }^{11 \mathrm{~b}}$ developed a novel $\mathrm{NaH}$ promoted domino reaction between thioaurones and crotonate-derived sulfonium salts. which has been the first example of using a crotonate-derived sulfonium salt as a $\mathrm{C} 3$ synthon in a $[4+3]$ annulation reaction. A variety of 2,5-dihydrobenzo [4,5] thieno [3,2-b] oxepines were obtained. $\mathrm{Li}^{11 \mathrm{c}}$ developed a novel $[4+3]$ annulation of iminoindoline-derived aza-dienes with crotonate sulfonium salts to construct azepino[2,3-b] indole cores. $\mathrm{He}^{11 \mathrm{~d}}$ has developed a $\mathrm{Cs}_{2} \mathrm{CO}_{3}$ promoted [4+3] cascade annulation reaction of crotonate-derived sulfur ylides with 2 -ylideneoxindoles to synthesize a series of oxepino [3,2-b] indoles. Inspired by the previous work, we envisioned a base promoted [4+3] domino annulation of crotonate-derived sulfur ylides with functional diene to synthesize a series of none-fused cycles including nitrogenheterocycles and carbocycles (Scheme 1c).

We evaluated our investigation with a model reaction between 1-azadiene 1a and crotonate-derived sulfur ylide $\mathbf{2 a}$ in the presence of $\mathrm{Cs}_{2} \mathrm{CO}_{3}$ in dichloromethane at room temperature for $1 \mathrm{~h}$ to obtain nitrogen-heterocycles 3a (X-ray crystallographic analysis, CCDC 2145522) in 95\% isolated yield (Table 1 , entry 1). Some screening data of the reaction conditions were shown in Table 1. This reaction could not occur without base participated (entry 2). We changed the base to $\mathrm{Et}_{3} \mathrm{~N}, \mathrm{DABCO}$, $\mathrm{K}_{2} \mathrm{CO}_{3}$, but an unsatisfactory result was acquired with the yield of $54 \%, 32 \%, 84 \%$ separately (entry 3 ). The different solvents such as MeCN, DMF also were investigated with the yield of $78 \%, 80 \%$ separately. When chose alcohols solvent such as $\mathrm{MeOH}$, less than $5 \%$ of the product was obtained (entry 4). We tried to reduce the amount of base to $1.0 \mathrm{eq}$, but the yield was decreased correspondingly to $48 \%$ (entry 5 ). When the temperature was raised to $60^{\circ} \mathrm{C}$, we found that the raw material 2a began to decompose and the by-products began to increase. So that leads to a decrease in the $25 \%$ yield of $\mathbf{3 a}$ (entry 6 ).

Table 1. Screening Data of the Reaction Conditions to Synthesize Nitrogen-Heterocycles ${ }^{\mathrm{a}}$

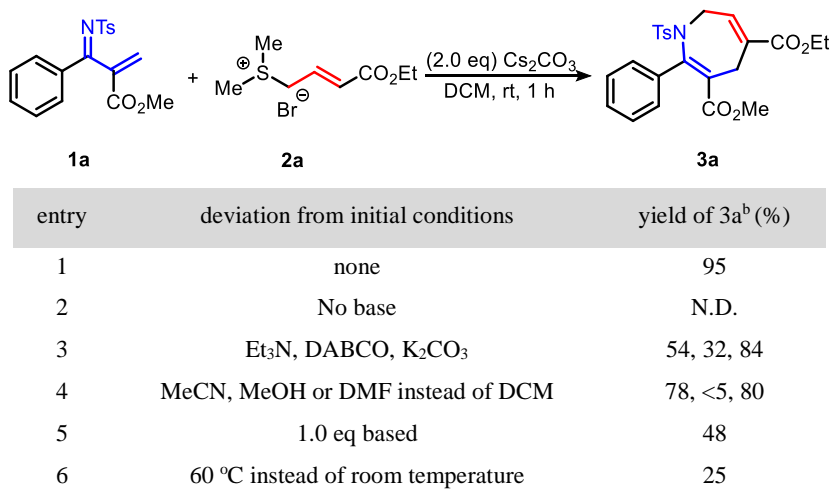

${ }^{a}$ Reaction conditions: 1a $(0.10 \mathrm{mmol}, 1.0 \mathrm{eq}), \mathbf{2 a}(0.12 \mathrm{mmol}, 1.2 \mathrm{eq})$, $\mathrm{Cs}_{2} \mathrm{CO}_{3}(0.20 \mathrm{mmol}, 2.0 \mathrm{eq}), \mathrm{DCM}(0.5 \mathrm{~mL})$, r.t, 1 h. N.D. $=$ not detected. $\mathrm{DMF}=\mathrm{N}, \mathrm{N}$-dimethylforma. ${ }^{b}$ Isolated yield was reported.

With these optimized conditions in hand, we then examined the generality of similar substrates. As shown in scheme 2, different substituent azadiene 1 was used under the standard condition. For example, Electron-donating group including paramethyl 3b (90\%), para-tertiary butyl 3e (81\%), meta-methoxy 3f $(75 \%)$, ortho-ethyl 3h (71\%) showed a satisfactory result. What's more, typical electron-withdrawing group such parafluorine 3d (45\%), trifluoromethoxy 3i $(52 \%)$ was also tolerated. Some halogen group, para-Cl 3c (74\%), meta-Br $\mathbf{3 g}$ (71\%). Alkyl substituted like cyclohexane $\mathbf{3 j}$ also showed a good yield of $68 \%$. To our delight, the ester group from azadiene showed good compatibility similarly represent in 3k and $\mathbf{3 I}$. Then, we evaluated the scope of crotonate-derived sulfur ylide (3m) by changing the ester group, which proved there is not any effect too. Replacing an ester group with a cyanide group could also trigger the reaction $(\mathbf{3 n})$.

\section{Scheme 2. Scope of the Nitrogen-Heterocycles ${ }^{\mathrm{a}}$}

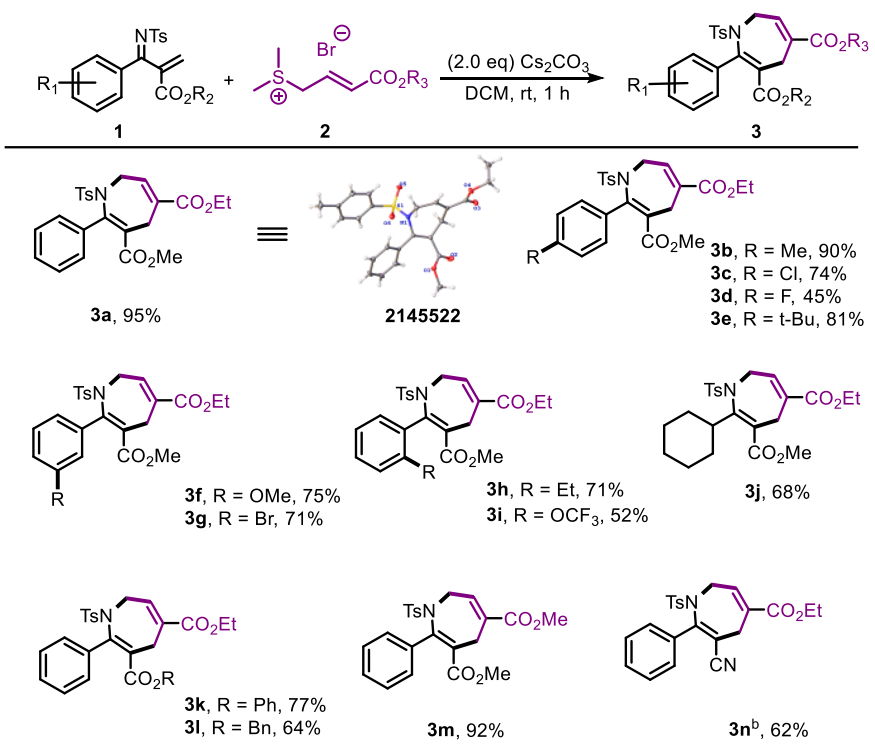

${ }^{a}$ Reaction conditions: $\mathbf{1}(0.10 \mathrm{mmol}, 1.0 \mathrm{eq}), \mathbf{2}(0.12 \mathrm{mmol}, 1.2 \mathrm{eq}), \mathrm{Cs}_{2} \mathrm{CO}_{3}$ $(0.2 \mathrm{mmol}, 2.0 \mathrm{eq}), \mathrm{DCM}(0.5 \mathrm{~mL})$, r.t, $1 \mathrm{~h}$. ${ }^{\mathrm{b}}$ React for $12 \mathrm{~h}$.

Subsequently, we focus on the structure of seven-membered carbocycles. The diene $\mathbf{4}$ and sulfur ylide $\mathbf{2}$ were chosen to participated in the [4+3] domino annulation under similar conditions (Specific experimental conditions were screened by reference to SI). Surprisingly, we could obtain the carbocycles 5a (X-ray crystallographic analysis, CCDC 2145568) with the isolated yield of $90 \%$ meanwhile. This exciting result encouraged us to continue our further exploration by employing the different substitutions (Scheme 3). Electron-donating group including methyl at para $\mathbf{5 b}$ or meta position $\mathbf{5 e}$ show a good result for over $92 \%, 89 \%$ yield separately. The electron-withdrawing group $\mathrm{CF}_{3} \mathbf{5 c}$ could also be tolerated towards this reaction. When move the fluorine group to ortho position, there was no any product can be observed $(\mathbf{5 g})$. Some halogen groups $(\mathbf{5 d}$ and 5f) performed a preferable result. Some representative heterocycles such as thiophene are also suitable for this reaction 5h. The ester group from diene and sulfur ylide showed no effect towards this reaction $\mathbf{5 i}$ and $\mathbf{5 j}$.

Based on our experimental results and previous related studies, ${ }^{11 b, 12}$ a possible mechanism for this type of [4+3] annulation reactions was proposed (Scheme 4). Firstly, deprotonation of

\section{Scheme 3. Scope of the Seven-membered Carbocycles}




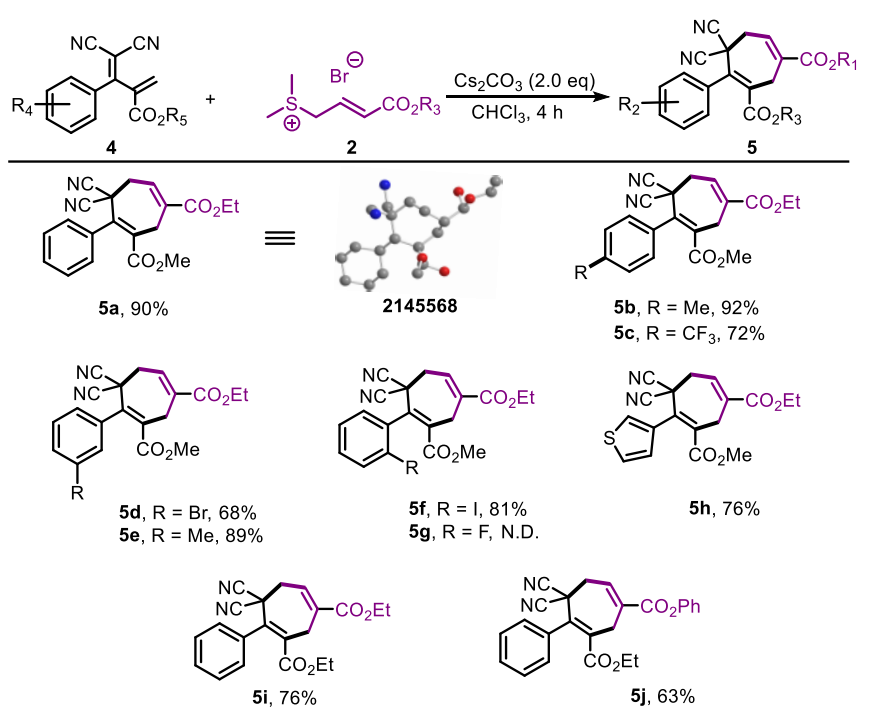

${ }^{a}$ Reaction conditions: 4 (0.10 mmol, $\left.1.0 \mathrm{eq}\right), 2$ (0.12 mmol, $\left.1.2 \mathrm{eq}\right), \mathrm{Cs}_{2} \mathrm{CO}_{3}$ (0.2 mmol, 2.0 eq), $\mathrm{CHCl}_{3}(0.5 \mathrm{~mL})$, r.t, 4 h.

crotonate-derived sulfur ylides $\mathbf{2 a}$ results in a carbanion allylic ylide intermediate $\mathrm{A}$ in the presence of a base (such as $\mathrm{Cs}_{2} \mathrm{CO}_{3}$, $\mathrm{NaH}$ ). Carbanion allylic ylide intermediates B is formed by tautomerism from sulfur ylide intermediate A. Then, an intermolecular Michael addition of carbanion allylic ylide intermediate $\mathrm{B}$ as $\mathrm{C} 3$ synthons to functional diene as the start step. Followed by the nucleophilic site of diene attacks the carbanion allylic ylide to implement a closed cycle process and one equivalent of $\mathrm{SMe}_{2}$ was separated from the system to complete the whole domino process. Finally, the highly functional none-fused cycles including nitrogen-heterocycles or carbocycles are obtained.

\section{Scheme 4. Plausible Reaction Mechanisma}

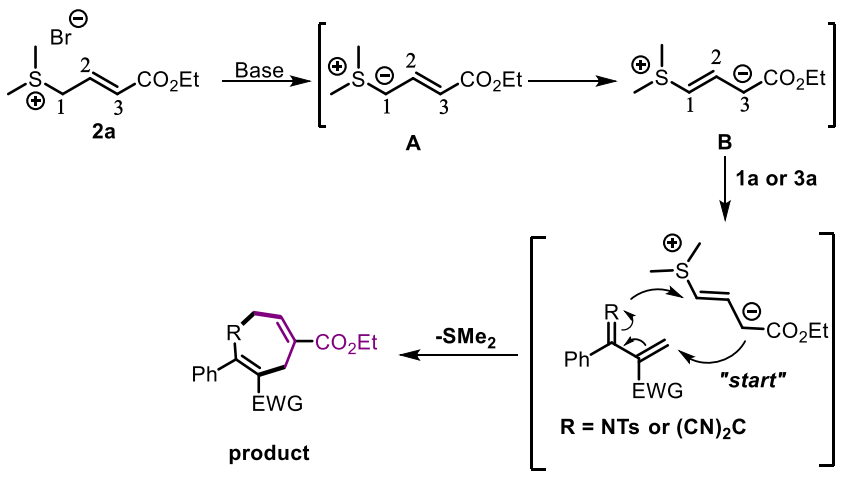

In summary, we have developed an inventive example of domino annulation reaction of crotonate-derived sulfur ylides and dienes to generate highly functional none-fused sevenmembered cycles such as nitrogen-heterocycles and carbocycles with moderate to excellent yields. The advantages of the current reaction include available and easy-synthesized materials, mild reaction conditions, good functional groups tolerance, and extensive substrate scope. In addition, this is also a supplementary to sulfur ylide chemistry as the $\mathrm{C} 3$ synthesizer, and we are confident that this type of reaction has important application potential in the synthesis of natural products and bioactive molecules.

\section{ASSOCIATED CONTENT}

\section{Supporting Information}

Experimental details, materials characterization and copies of relevant NMR spectra for all products, this material is available free of charge via the Internet at http://pubs.acs.org.

\section{AUTHOR INFORMATION}

\section{Corresponding Author}

* Yang Liu - Frontier Institute of Science and Technology (FIST), Xi'an Jiaotong University, Xi'an, Shanxi 710054, P. R. China.

Email: Yang_Liu.Chem@outlook.com orcid.org/0000-0003-0036-6232

\section{Author}

Yang Liu - Frontier Institute of Science and Technology (FIST), Xi'an Jiaotong University, Yanxiang Road 99, Xi'an, Shaanxi, 710054, P.R. China.

Email: Yang_Liu.Chem@outlook.com orcid.org/0000-0003-0036-6232

Joost Berkhong - Frontier Institute of Science and Technology (FIST), Xi'an Jiaotong University, Yanxiang Road 99, Xi'an, Shaanxi, 710054, P.R. China.

Email: J.Berkhong_chem@outlook.com

Notes

The authors declare no competing financial interest.

\section{ACKNOWLEDGMENT}

We thank the Priority Academic Program Development of Shaanxi Higher Education Institutions and Postdoctoral research fund of $\mathrm{Xi}$ 'an Jiaotong University.

\section{REFERENCES}

(1) (a) Trost, B. M.; Melvin, L. S. (eds) Sulfur Ylides (Academic Press, 1975). (b) An, -H. L.; Li, -X. D.; Varinder, K. A. Asymmetric Ylide Reactions: Epoxidation, Cyclopropanation, Aziridination, Olefination, and Rearrangement. Chem. Rev. 1997, 97, 2341-2372. (c) Eoghan, M. M.; Eddie, L. M.; Ona, I.; Michael, A. S.; Samantha, L. R.; Varinder, K. A. Chalcogenides as Organocatalysts. Chem. Rev. 2007, 107, 5841-5883. (d) Xiu, -L. S.; Yong, T. Ylide-Initiated Michael Addition-Cyclization Reactions beyond Cyclopropanes. Acc. Chem. Res. 2008, 41, 937-948. (e) Lu, L. Q.; Li, T. R.; Wang, Q.; Xiao, W. Beyond sulfide-centric catalysis: recent advances in the catalytic cyclization reactions of sulfur ylides. Chem. Soc. Rev. 2017, 46, 4135-4149

(2) Kürti, L.; Czakó, B. Strategic Applications of Named Reactions in Organic Synthesis (Elsevier Academic Press, 2005).

(3) (a) Roxanne, K. K.; David, W. C. M. Enantioselective Organocatalytic Cyclopropanations. The Identification of a New Class of Iminium Catalyst Based upon Directed Electrostatic Activation. J. Am. Chem. Soc. 2005, 127, 3240-3241. (b) Antti, H.; Per, I. A. Tetrazolic Acid Functionalized Dihydroindol: Rational Design of a Highly Selective Cyclopropanation Organocatalyst. J. Org. Chem. 2007, 72, 5874 5877. (c) Jing, W.; Xiao, H. L.; Shun, X. D.; Li, I. L.; Xiao, M. F. 
Asymmetric Organocatalytic Cyclopropanation of Cinnamone Derivatives with Stabilized Sulfonium Ylides. J. Org. Chem. 2013, 78, 63226327.

(4) (a) Toshihiko, S.; Akitake, Y.; Shigeki, M.; Masakatsu, S. Catalytic Asymmetric Synthesis of 2,2-Disubstituted Terminal Epoxides via Dimethyloxosulfonium Methylide Addition to Ketones. J. Am. Chem. Soc. 2008, 130, 10078-10079. (b) Toshihiko, S.; Akitake, Y.; Shigeki, M.; Masakatsu, S. Enantioselective Synthesis of 2,2-Disubstituted Terminal Epoxides via Catalytic Asymmetric Corey-Chaykovsky Epoxidation of Ketones. Moleculars. 2012, 17, 1617-1634. (c) Toshihiko, S.; Gang, L.; Shigeki, M.; Masakatsu, S. Catalytic Asymmetric Synthesis of 2,2-Disubstituted Oxetanes from Ketones by Using a One-Pot Sequential Addition of Sulfur Ylide. Angew. Chem., Int. Ed. 2009, 48, 1677-1680

(5) (a) Dai, L.-X.; Hou, X.-L.; Zhou, Y.-G. Stereoselective synthesis of three-membered ring compounds via ylide routes. Pure Appl. Chem. 1999, 71, 369-376. (b) Aggarwal, V. K.; Winn, C. L. Catalytic, Asymmetric Sulfur Ylide-Mediated Epoxidation of Carbonyl Compounds: Scope, Selectivity, and Applications in Synthesis. Acc. Chem. Res. 2004, 37, 611-620. (c) Zhu, B. H.; Zheng, J. C.; Yu, C. B.; Sun, X. L.; Zhou, Y. G.; Shen, Q.; Tang, Y. One-Pot Highly Diastereoselective Synthesis of cis-Vinylaziridines via the Sulfur Ylide-Mediated Aziridination and Palladium (0)-Catalyzed Isomerization. Org. Lett. 2010, 12, 504-507.

(6) Liang, -Q. L.; Fang, L.; Jing, A.; Ying, C.; Jia, -R. C.; Wen, -J. $\mathrm{X}$. Hydrogen-Bond-Mediated Asymmetric Cascade Reaction of Stable Sulfur Ylides with Nitroolefins: Scope, Application and Mechanism. Chem.- Eur. J. 2012, 18, 4073-4079.

(7) Jian, J. Z.; Gary, B. S. Ylidions: a new reactive intermediate prepared by photosensitized one-electron oxidation of phenacyl sulfonium ylides. J. Am. Chem. Soc. 1989, 111, 7149-7155. (b) Xu, -D. X.; Liang, -Q. L.; Wen, -Q. L.; Dong, -Z. C.; Yu, -H. Z.; Li, -Z. W.; Wen, -J. X. Visible-Light-Driven Photocatalytic Activation of Inert Sulfur Ylides for 3-Acyl Oxindole Synthesis. Chem.- Eur. J. 2016, 22, 8432-8437. (c) Stacey, A. S.; Melanie, H.; William, S. J. S, $C$-Sulfonium Ylides from Thiophenes: Potential Carbene Precursors. J. Am. Chem. Soc. 2007, 129, 15746-15747.

(8) K, C. N.; Ya, -P. S.; Ramakrishna, G.; Biswadip, B.; David, Y. K. C. Total Synthesis of the Originally Proposed and Revised Structures of Palmerolide A and Isomers Thereof. J. Am. Chem. Soc. 2008, 130, 3633-3644. (b) Francisco, S.; Francisca, M. G.; Samy, C.; Laura, M. O.; Antonio, S. R. Chiral Sulfur Ylides for the Synthesis of Bengamide E and Analogues. J. Org. Chem. 2010, 75, 5526-5532.

(9) For typical report is listed: (a) Kun, L.; Jian, H.; Hui, L.; Xiao, F. T. Amine-catalyzed formal $(3+3)$ annulations of 2 -(acetoxymethyl) buta-2,3-dienoate with sulfur ylides: synthesis of $4 \mathrm{H}$-pyrans bearing a vinyl sulfide group. Chem. Commun. 2012, 48, 2900-2902. (b) Søren, K.; Troels, S. Gold-Catalyzed Carbene Transfer to Alkynes: Access to 2,4-Disubstituted Furans. Angew. Chem., Int. Ed. 2012, 51, 4681-4684. (c) Tian, -R. L.; Fen, T.; Liang, -Q. L.; Yi, W.; Ya, -N. Wang.; Yi, -Y. L.; Qing, -Q. Y.; Jia, -R. C.; De, -Q. S.; Wen, -J. X. Asymmetric trapping of zwitterionic intermediates by sulphur ylides in a palladium-catalysed decarboxylation-cycloaddition sequence. Nat. Commun. 2014, 5, 5500-5510. (d) Qiang, W.; Xiao, Q.; Liang, -Q. L.; Tian, -R. L.; Zhi, -G. Y.; Kai, Z.; Bin, -J. L.; Yu, L.; Wen, -J. X. Iron-Catalyzed Decarboxylative (4+1) Cycloadditions: Exploiting the Reactivity of Ambident Iron-Stabilized Intermediates. Angew. Chem., Int. Ed. 2016, 55, 2840-2844. (e) Qiang, W.; Tian, -R. L.; Liang, -Q. L.; Miao, -M. L.; Kai, Z.; Wen, -J. X. Catalytic Asymmetric [4+1] Annulation of Sulfur Ylides with Copper-Allenylidene Intermediates. J. Am. Chem. Soc. 2016, 138, 8360-8363.

(10) For typical report is listed: (a) Wang, Q.-G.; Deng, X.-M.; Zhu, B.-H.; Ye, L.-W.; Sun, X.-L.; Li, C.-Y.; Zhu, C.-Y.; Shen, Q.; Tang, Y. Tandem Michael Addition/Ylide Epoxidation for the Synthesis of Highly Functionalized Cyclohexadiene Epoxide Derivatives. J. Am. Chem. Soc. 2008, 130, 5408-5409. (b) Zhu, B.-H.; Zhou, R.; Zheng, J.-
C.; Deng, X.-M.; Sun, X.-L.; Shen, Q.; Tang, Y. Highly Selective Ylide-Initiated Michael Addition/Cyclization Reaction for Synthesis of Cyclohexadiene Epoxide and Vinylcyclopropane Derivatives. J. Org. Chem. 2010, 75, 3454-3457. (c) Chen, Z.-L.; Zhang, J.-L. Highly Functionalized 4-Alkylidenebicyclo[3.1.0]hex-2-enes by Tandem Michael Addition and Annulation of Electron-Deficient Enynes. Chem. - Asian J. 2009, 4, 1527-1529

(11) (a) Peng, J.; You, H. Sequential Annulation Domino Reaction of Sulfur Ylides and $\alpha, \beta$-Unsaturated Cyclic Ketimines: Synthesis of Cyclic 2-Alkenyl Aziridines. Org. Lett. 2016, 18, 2475-2478. (b) You, Z.; Ai, Y.; Ji, J.; Shan, M.; Ke, L.; Yin, W.; Xiao, M. NaH promoted [4+3] annulation of crotonatederived sulfur ylides with thioaurones: synthesis of 2,5-dihydrobenzo[4,5]thieno[3,2-b]oxepines. Chem. Commun. 2017, 53, 10672-10675. (c) Jun, -L. L.; Qing, -S. D.; Kai, -C. Y.; Yue, L.; Xiang, Z.; Hai, -J. L.; Cheng, P.; Wei, H.; Qing, -Z. L. Construction of Azepino[2,3-b]indole Core via Sulfur Ylide Mediated Annulations. Org. Lett. 2018, 20, 7628-7632. (d) Xing, -H. F.; Yong, -L. Z.; Fen, -F. Y.; Xiang, G.; Zong, -Q. L.; Da, -P. W.; Meng, Z.; Yuan, Y. Y.; Bin, H. Construction of Oxepino[3,2-b]indoles via [4+3] Annulation of 2-Ylideneoxindoles with Crotonate-Derived Sulfur Ylides. Adv. Synth. Catal. 2021, 363, 1-8.

(12) (a) Jun, C.; Peng, J.; You, H. Divergent Domino Reactions of Sulfur Ylides: Access to Functionalized Six- and Seven-Membered Nitrogen-Heterocycles. Org. Lett. 2018, 20, 6715-6718. (b) Matam, P.; Maneesh, K. R. S.; Attunuri, N.; Jagadeesh, B. N.; Maddi, S. R. Regioselective benzannulation of allylic sulfur ylides with ynones: a rapid access to substituted thioanisoles. Chem. Commun. 2020, 56, 1345713460. (c) Lakshminarayana, S.; Irishi, N. N. N. (3 + 3) Annulation of Nitroallylic Acetates with Stabilized Sulfur Ylides for the Synthesis of 2-Aryl Terephthalates. J. Org. Chem. 2018, 83, 9471-9477. 